Article

\title{
Expansion of Industrial Parks in the Beijing-Tianjin-Hebei Urban Agglomeration: A Spatial Analysis
}

\author{
Lei Kang ${ }^{1}$ and Li Ma ${ }^{1,2, *}$
}

1 Key Laboratory of Regional Sustainable Development Modeling, Institute of Geographic Sciences and Natural Resources Research, Beijing 100101, China; kanglei@igsnrr.ac.cn

2 College of Resources and Environment, University of Chinese Academy of Sciences, Beijing 100049, China

* Correspondence: mali@igsnrr.ac.cn

check for updates

Citation: Kang, L.; Ma, L. Expansion of Industrial Parks in the BeijingTianjin-Hebei Urban Agglomeration: A Spatial Analysis. Land 2021, 10, 1118. https://doi.org/10.3390/ land 10111118

Academic Editor: Piyush Tiwari

Received: 13 September 2021

Accepted: 18 October 2021

Published: 21 October 2021

Publisher's Note: MDPI stays neutral with regard to jurisdictional claims in published maps and institutional affiliations.

Copyright: (c) 2021 by the authors. Licensee MDPI, Basel, Switzerland. This article is an open access article distributed under the terms and conditions of the Creative Commons Attribution (CC BY) license (https:// creativecommons.org/licenses/by/ $4.0 /)$.
Abstract: Today, China is witnessing large-scale expansion of industrial parks. Rapid urbanization has resulted in the planning, development, and functional transformation of large industrial parks. Some of the expansions have occurred in core areas, while others involved the establishment of new park spaces in peripheral areas. This study examines industrial parks' spatial expansion in the BeijingTianjin-Hebei urban agglomeration and supplements the currently limited spatial expansion analyses of groups of development zones within specific regions. From the perspective of land use change, the study characterizes the spatial expansion of industrial parks in the three periods 1990-2000, 2000-2010, and 2010-2015. Results reveal the following: (1) During the three periods, the footprint of major industrial parks in Beijing-Tianjin-Hebei increased continuously, whereas the average annual growth rates diminished by $11.51 \%, 8.17 \%$, and 3.38\% for 1990-2000, 2000-2010, and 2010-2015, respectively. (2) In terms of spatial layout, the density of industrial parks has always been high in Beijing and Tianjin, and it increased over the three periods in Hebei, with more industrial parks established in the southeastern and fewer in the northern regions. (3) Regarding expansion modes, the period 1990-2000 witnessed several edge-expansions in core areas, such as Beijing and Tianjin, and limited expansions in peripheral cities; in 2000-2010, mainly edge- and infilling expansions occurred in core cities and characteristically outlying expansions in peripheral ones. In 2010-2015, infilling expansions took place in core cities and edge-expansions of established industrial parks occurred in small and medium-sized cities. Identifying the expansion modes is instrumental in differentiating industrial park development paths and optimizing an entire region's spatial planning for industrial parks.

Keywords: industrial parks; spatial expansion; modes; Beijing-Tianjin-Hebei urban agglomeration

\section{Introduction}

The progress of economic globalization and the international division of labor and trade have facilitated the emergence and development of various development zones, which has gradually become an important policy tool to promote local and regional development [1-3]. China started establishing urban development zones more than 30 years ago and has seen a substantial increase in development zones since 1992, the "Development Zone Fever" [4,5], including economic and technological development zones, high-tech development zones, free-trade zones, export processing zones, and industrial parks. The common idea for these practices is that in some circumstances, it might be helpful to isolate certain local areas and offer special conditions to companies to stimulate industrial development, innovation, and competition. China has achieved massive success with this economic land tool [6]. Development zones have been remarkably effective in enhancing local economic development, attracting foreign investments, and enabling the introduction of advanced technologies. Today, these zones are an important means of promoting urbanization in China and increasingly larger industrial parks of various types are being planned 
and built in these areas [7]. So, more importantly, China's rapid urbanization is closely related to the proliferation of different kinds of development zones. It has dramatically influenced the national land use and land cover changes, fostering urban expansion [3]. We need to examine the impact of changes in human socio-economic activities on land use changes from the perspective of development zones.

Studies on external economies, location choices, industrial clusters, growth poles, and spatial layouts provide adequate theoretical guidelines for practices related to industrial park expansion [8-13]. Most case studies analyze and examine microscale mechanisms behind the emergence and development of industrial parks [14-16]. There are also numerous theoretical and empirical studies on perspectives such as policy implementation, regional economy, and industrial economy and many focus on issues such as industrial positioning, productivity, organizational management, optimization and transformation, development mode and strategies, and sustainable development [17-19]. Some spatial studies aim to reveal the spatial effects of the development of industrial parks and the characteristics and patterns of urban spatial structure evolution driven by park development $[20,21]$. Research indicates that development zone construction could have an impact on land use efficiency [22,23]. In comparison with foreign countries, the scales of industrial parks in China are generally larger. However, these large development zones have a much lower average output per square meter than the international level because the competition among businesses in the parks suppresses productivity [24] and the parks' expansions are often associated with high volumes of idle or wasted land $[25,26]$. In an emerging industrial park, the growing demand for land space, the requirements of urban development, national land policy adjustments, and the need to develop the industrial park itself stimulate an increase in industrial land and expansion $[27,28]$. These negatively affect the spatial scale and development efficiency of industrial parks [29]. Many national industrial parks expand by incorporating several parks. This inappropriate expansion results from inefficient land use, local governments' urgency in pursuing development, and an unreasonable allocation of resources [30]. With the goal of targeting prominent issues and restrictive bottlenecks that emerge during industrial park development, many studies examine the problems of spatial optimization and transformation; discuss modes of spatial optimization in the dimensions of principles and ideas, spatial structure, form development, and land use unit organizations [31-33]; and propose strategies for spatial optimization by identifying the requirements of, and dilemmas in, spatial development against the changes in the economic growth mode, such as industrial upgrading, functional transformation, intensive use of spaces, and building reconstruction and reuse [34].

After examining the mechanisms behind industrial parks' spatial expansion, studies have attributed the variation in and development of spatial structures and forms to the shift from unitary to multiple functions along with the aggregation of industrial economic activities and urban services $[3,35]$. Moreover, it is suggested that due to the continuous development of industrial parks, the in situ expansion of industrial spaces promotes land development. Based on the industrial and economic interdependencies and radiation effects between core cities and peripheral areas, the expansion can trigger changes in the land use scale and spatial structure and forms in a large territorial zone [32,36]. Further, the regulations for land use policy and planning do not allow an individual park to expand infinitely in a territorial space. When a location becomes unable to accommodate more investors, the surrounding counties and cities use industrial linkage to build new parks to assume supportive roles. In essence, spatial evolutions are driven by the evolution, upgradation, reorganization, and overflow of park functions. Since spaces are the carrier of functions and land is the carrier of the industrial park [33], it is critical to examine industrial parks' spatial layouts and land expansions before addressing issues such as their spatial optimization and functional transformation.

In the research on the spatial expansion of industrial parks, Zhang pointed out that the expansion of industrial parks presents the characteristics of large-scale, high-speed development of a human settlement space driven by an industrial space and low land use 
intensiveness. She believes that the spatial expansion of the parks emphasizes quantity rather than quality and proposes that economic parks pay more attention to the quality of space expansion and focus on intensive growth [20]. Based on the analysis of the spatial scale and benefits of China's urban development zones, Wang et al. believe that development zones are responsible for the expansion of urban space and have the characteristics of "aperture" and "honeycomb" effects [25]. Geng finds that, driven by local interests and poor planning control, there are problems in the construction of development zones in China, such as the impulse for spatial expansion, extensive land use, and chaotic regional spatial development order [37]. Taking the Hangzhou Economic and Technological Development Zone as an example, Rao et al. studied the spatial development characteristics and problems of an industrial park in the transition to a new city. They pointed out that industrial parks have the characteristics of spatial development, such as the transformation of the spatial scale from small to large and the transformation of the spatial structure from a single cluster to multiple clusters [38]. However, most studies on the patterns of spatial expansions of industrial parks are mainly qualitative and focus on prominent issues and, thereby, propose optimization strategies and regulation paths for industrial parks' spatial structures $[39,40]$. Further, some important microscale studies are only case studies [41]. From the regional perspective, there are often numerous industrial parks within a region. There are many differences among different industrial parks. For example, the spatial expansion characteristics of industrial parks in different locations may be different. Therefore, although some scholars have identified certain spatial extension rules of industrial parks based on case studies, relevant conclusions may not be universally applicable. Additionally, due to different economic development stages, the characteristics of spatial evolution on the macroscale of groups of industrial parks within specific regions might differ from those of an individual park. For microscopic case studies to effectively represent regional characteristics, the complete, long-term, and comprehensive urban construction data should be obtained. However, it is always difficult to get such data and materials. Additionally, relevant quantitative analyses require the use of accurate, intricate, and robust approaches to reach meaningful conclusions. As a result, studies focusing on long time series and quantitative expansion analyses of groups of industrial parks within specific regions are fewer. Due to the advent of innovation globalization and the transformation of China's economy into a high-quality development economy, the spatial optimization of allocation of functions is an effective technique whereby most of the country's industrial parks can avoid the recession caused by a weakening momentum after rapid development. Therefore, to efficiently allocate resources and achieve productive labor division and thereby promote industrial park transformation, we must first perform long-term monitoring of the spatial expansion of numerous industrial parks within specific regions to understand the macroexpansion pattern.

Since the 1990s, the Beijing-Tianjin-Hebei urban agglomeration has been recording one of the highest urbanization rates in China. Driven by industrialization, the industrial production spaces have undergone remarkable changes in scale and speed along with the expansion of urban spaces over the years. Accordingly, the industrial parks, which are important carriers of industrial production, have undergone considerable spatial expansion and transformation under the pressures of urbanization and industrialization. The industrial development in the urban agglomeration heavily depended on "park economy." Industrial parks also played an important role in the region's industrial planning and spatial optimization. This study explores industrial parks' spatial variations in the BeijingTianjin-Hebei urban agglomeration in the context of regional development. In this study, comprehensive data on land use changes in the urban agglomeration's industrial parks for the three periods 1990-2000, 2000-2010, and 2010-2015 were captured and analyzed using remote sensing and geographic information system (GIS) techniques. This study supplements the findings of earlier spatial analyses of industrial parks by providing a holistic picture of spatial expansion. The results are valuable since they propose countermeasures 
and paths for the appropriate optimization of industrial parks' spaces based on the status and dynamics of these zones.

\section{Materials and Methods}

\subsection{Definition and Overview of the Study Area}

An urban agglomeration is defined as a group of cities consisting of one or more mega-cities at the core of at least three other large cities within a specific geographical area, all of which rely on a developed transport and communication infrastructure network, have a compact spatial organization, and have close economic links, ultimately leading to the formation of conurbations and a high degree of integration [42]. The Beijing-Tianjin-Hebei urban agglomeration is one of the largest urban agglomerations which is the current foci of China's new urbanization strategy. Under the multiple effects of regional location advantages, policy advantages, and economic advantages, the Beijing-Tianjin-Hebei urban agglomeration has formed a modern industrial system, a highly developed infrastructure network, and a close relationship with the world economy. The agglomeration belongs to the important node in the world city network, the leader of national technology and high-tech industrialization, the center of domestic and foreign financial institutions, and the important world-class urban agglomeration in East Asia. In our study, 13 cities in Beijing, Tianjin, and Hebei are defined as the Beijing-Tianjin-Hebei urban agglomeration, according to a series of works [43-45], which is consistent with the existing research results and conforms to China's development strategy positioning. Based on the permanent population of the municipal districts in 2015, the Beijing-Tianjin-Hebei urban agglomeration has formed a multi-level urban system consisting of megacities, large cities, medium cities, and small cities (Table 1). Among them, Beijing and Tianjin are super-large cities. There are 4 large cities, with a population of 1 to 5 million, namely, Tangshan, Shijiazhuang, Handan, and Baoding, and 6 medium-sized cities, with a population of 500,000 to 1 million, namely Qinhuangdao, Xingtai, Zhangiiakou, Langfang, Chengde, and Cangzhou. The only small city, with a population of less than 500,000 , is Hengshui.

Table 1. The hierarchical scale structure of the Beijing-Tianjin-Hebei urban agglomeration.

\begin{tabular}{ccccc}
\hline Level & Type & Population & Number of Cities & Cities \\
\hline 1 & Super-large cities & $>10$ million & 2 & Beijing, Tianjin \\
2 & Megacities & 5 million-10 million & $/$ & $/$ \\
3 & Large cities & 1 million-5 million & 4 & Tangshan, Shijiazhuang, Handan, Baoding \\
4 & Medium-sized cities & $500,000-1$ million & 6 & Qinhuangdao, Xingtai, Zhangjiakou, \\
5 & Small cities & $<500,000$ & 1 & Hengshui \\
\hline
\end{tabular}

\subsection{Identification of Major Industrial Parks and the Acquisition of Spatial Data}

The spatial distribution vector data of major industrial parks examined in this study were obtained by vectorizing remote sensing images through visual interpretation. The study considers all kinds of national- and provincial-level special economic zones covering the Beijing-Tianjin-Hebei agglomeration, including high-tech development zones, economic and technological development zones, and industrial parks. First, from the Public Catalog of Approved Development Zones in China (2018 Edition) (https:/ /www.ndrc. gov.cn/fggz/lwzjw / zcfg/201803/t20180302_1047056.html?code=\&state=123, accessed on 26 February 2018), we obtained the list of industrial parks above the provincial level in Beijing, Tianjin, and Hebei, as well as the longitude and latitude coordinates of each park's management committee office, which helped us determine the parks' spatial locations. Further, Land-SAT TM/ETM remote sensing images of Beijing, Tianjin, and another 11 prefecture-level cities in Hebei were collected at 4 time points (1990, 2000, 2010, and 2015). The image data were sourced from the United States Geological Survey (USGS) with a resolution of $30 \mathrm{~m}$. Using GIS and remote sensing technologies and high-resolution Google Earth satellite image maps of relevant regions and non-remote-sensing information, 
such as the planning maps of some parks, vector data on the spatial distribution of industrial parks in the Beijing-Tianjin-Hebei urban agglomeration for the years 1990, 2000, 2010, and 2015 were obtained through manual and visual interpretations on computer screens (Figure 1).
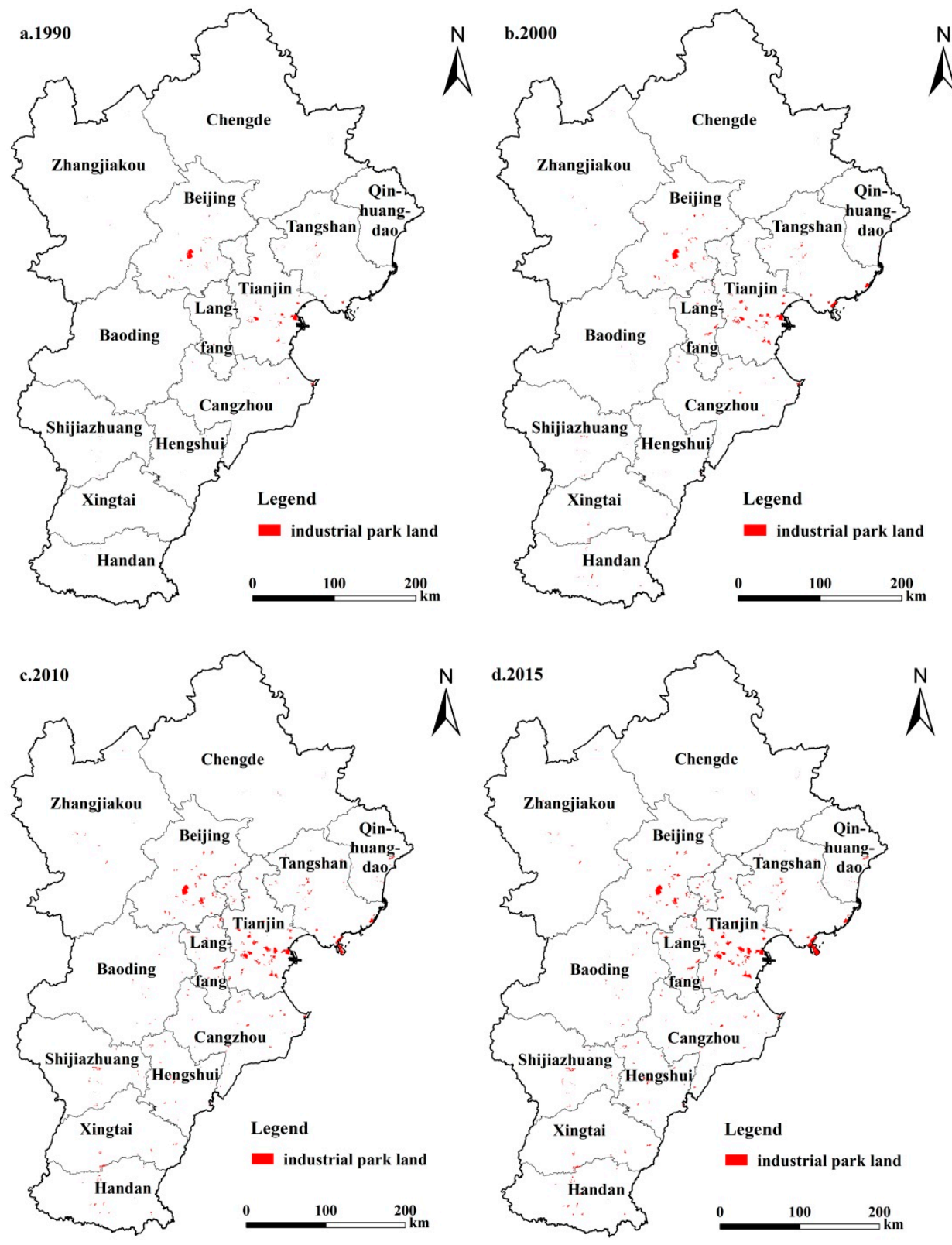

Figure 1. Spatial distribution of major industrial parks in the Beijing-Tianjin-Hebei region from 1990 to 2015 .

\subsection{Diffusion Trend Analysis of Industrial Parks' Spatial Distribution}

In this study, the diffusion trend of industrial parks in the Beijing-Tianjin-Hebei urban agglomeration is described using kernel density estimation (KDE). According to Tobler's First Law of Geography, all geographical objects or attributes in a spatial distribution are related to each other; the shorter the distance, the closer the relationships. Based on the law, KDE is fundamentally a data interpolation process using discrete geographical objects. The density distribution mode can be characterized using the distance diminishing effect. The visualization tool powered by the ArcGIS platform enables the visual representation of 
the spatial changes in geographical objects' distribution density. The kernel density was calculated using the following equation:

$$
f(x, y)=\frac{1}{n h^{2}} \sum_{i=1}^{n} k\left(\frac{d_{i}}{h}\right)
$$

where $f(x, y)$ is the density estimation for the location $(x, y) ; k\left(\frac{d_{i}}{h}\right)$ is the kernel density function, where $d_{i}$ is the distance between the location $(x, y)$ and the $i$-th observation point; $h$ is the distance diminishing threshold; and $n$ is the number of point features observed within the threshold. KDE can be used to analyze point or line features. Since the data collected for this study were vectorized plane data associated with industrial parks, they were converted to point features, which were then processed using the Kernel Density Tool in the ArcGIS spatial analysis toolbox. For this study, we first extracted the gravity centers of spots representing industrial parks in the Beijing-Tianjin-Hebei urban agglomeration in 1990, 2000, 2010, and 2015. After several trial calculations, we finally set the distance diminishing threshold $h$ at $20 \mathrm{~km}$. The weights were set as the spot area for the kernel density analysis of industrial parks' land use. Natural breaks were used to classify the industrial parks into low-density, low- to moderate-density, moderate-density, moderateto high-density, and high-density zones. In this manner, we obtained the distribution of industrial parks' land use density in the Beijing-Tianjin-Hebei urban agglomeration for the specified years.

\subsection{Identification of Industrial Parks' Expansion Modes}

There are three main spatial modes of landscape expansions, infilling, edge, and outlying, and there are also variants or hybrids of the three modes. As a landscape typically dominated by expansion, urban land use develops the general characteristics of landscape expansion, including the aforementioned three modes. This study uses the landscape expansion index (LEI) [46] to identify the static spatial characteristics of landscape patterns and the process and modes of dynamic change in landscape patterns at different points of time. The index is defined and calculated based on the buffer zone of new landscape spots within a certain distance instead of considering the minimum bounding box. It is calculated using the following formula:

$$
\mathrm{LEI}=100 * \frac{A_{o}}{A_{o}+A_{v}}
$$

where $A_{o}$ represents the area of the original landscape spot in the buffer zone and $A_{v}$ is the area of other landscapes (open space) in the buffer zone. Referring to the division results of LEI from Liu's team, we determine the LEI thresholds for various types of expansion. When $0 \leq \mathrm{LEI}<2$, the new patch belongs to outlying expansion. When $2 \leq \mathrm{LEI} \leq 50$, the newly added patch belongs to edge-expansion, and when $50<\mathrm{LEI} \leq 100$, the newly added patch belongs to infilling expansion.

\section{Results}

\subsection{Evolution of Land Use Scale of Industrial Parks}

In the industrialization process of the Beijing-Tianjin-Hebei agglomeration, the establishment and development of various industrial parks provided the spatial carrier for industrial development and transformation and played an indispensable role in promoting regional economic development. Statistical data on the spatial scale of industrial park land use for the four years of 1990, 2000, 2010, and 2015 (Figure 2) reveals that the total land area of major industrial parks in the agglomeration is increasing continuously. For specific years, statistics show that the total land area of major industrial parks in 1990 was $262.24 \mathrm{~km}^{2}$, that is, only $0.12 \%$ of the agglomeration's total land area. In 2000, the parks' total area increased to $564.18 \mathrm{~km}^{2}$, that is, $0.26 \%$ of the agglomeration's total area, which is more than double the value for 1990 . The area exceeded $1000 \mathrm{~km}^{2}$ in 2010, reaching $1024.96 \mathrm{~km}^{2}$, and 
increased to $1198.32 \mathrm{~km}^{2}$ in 2015 . Over the past 25 years, the area of land used for major industrial parks in the Beijing-Tianjin-Hebei region has increased by more than four times. With respect to growth rates, the average annual increase in land for major industrial parks was $30.2 \mathrm{~km}^{2}$ during 1990-2000, with an average annual growth rate (AAGR) of $11.51 \%$, and $46.08 \mathrm{~km}^{2}$ during 2000-2010, with an AAGR of 8.17\%. In 2010-2015, the AAGR was $3.38 \%$. It is evident that the growth rates are decreasing with an increase in land expansion for major industrial parks in the Beijing-Tianjin-Hebei urban agglomeration. To some extent, it shows that the spatial evolution of industrial park spaces is evolving toward a more intensive and efficient direction with the continuous advancement of urbanization and industrialization.

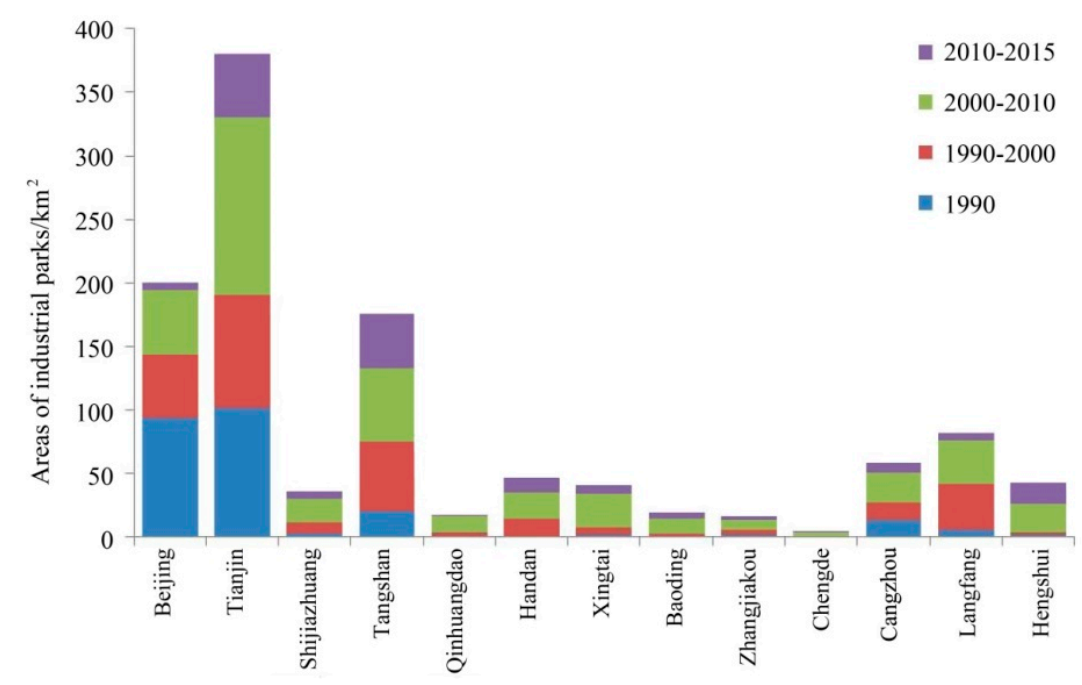

Figure 2. Areas and expansion scale of industrial parks in Beijing-Tianjin-Hebei urban agglomeration from 1990 to 2015.

Moreover, we calculated the annual expansion intensity of industrial parks by city (Table 2), which is the percentage of each city's added area of industrial parks in unit time to its total land area. For industrial parks in the Beijing-Tianjin-Hebei urban agglomeration, the expansion intensity first increased and then decreased in all the four time points. The period 2000-2010 recorded the strongest expansion in the last 25 years. During this period, Tianjin, Langfang, Tangshan, and Beijing were the top four cities with high to low land expansion intensities, with results of $0.081,0.059,0.044$, and 0.032, respectively. After 2000, except for Tangshan and Hengshui, the intensity decreased or plateaued after peaking in 2000-2010. Specifically, in the periods 2000-2010 and 2010-2015, Tianjin had the highest intensity values ( 0.127 and 0.092 , respectively) among the cities. Furthermore, in the latter period, the intensity of Tianjin decreased significantly compared to the earlier period but was still considerably higher than the intensities of other cities in the same period. During the two periods, Beijing and Langfang recorded significant changes in intensity, from 0.034 and 0.058 to 0.008 and 0.020 , respectively. In all the periods, Zhangiiakou and Chengde recorded the lowest intensity.

Generally, from 2000 to 2015, in the Beijing-Tianjin-Hebei region, more industrial parks started actively expanding the land used, showing an outward trend. In southern cities, such as Cangzhou, Hengshui, Xingtai, and Handan, the development of industrial parks occurred at a rapid rate for more than 20 years, whereas in the northern cities of Zhangjiakou and Chengde, the expansion was relatively moderate. For the entire agglomeration, the spatial pattern of multi-center and scattered expansion became increasingly apparent. 
Table 2. Intensity of industrial park land expansion in Beijing-Tianjin-Hebei urban agglomeration from 1990 to 2015.

\begin{tabular}{cccc}
\hline & $\mathbf{1 9 9 0 - 2 0 0 0}$ & $\mathbf{2 0 0 0 - 2 0 1 0}$ & $\mathbf{2 0 1 0 - 2 0 1 5}$ \\
\hline Beijing & 0.032 & 0.034 & 0.008 \\
Tianjin & 0.081 & 0.127 & 0.092 \\
Shijiazhuang & 0.007 & 0.014 & 0.010 \\
Tangshan & 0.044 & 0.045 & 0.067 \\
Qinhuangdao & 0.004 & 0.018 & 0.000 \\
Handan & 0.011 & 0.019 & 0.019 \\
Xingtai & 0.005 & 0.023 & 0.011 \\
Baoding & 0.001 & 0.005 & 0.005 \\
Zhangjiakou & 0.001 & 0.002 & 0.001 \\
Chengde & 0.000 & 0.001 & 0.000 \\
Cangzhou & 0.010 & 0.018 & 0.012 \\
Langfang & 0.059 & 0.058 & 0.020 \\
Hengshui & 0.002 & 0.027 & 0.040 \\
\hline
\end{tabular}

\subsection{Spatial Diffusion Characteristics of Industrial Parks}

The results of kernel density analysis of the industrial parks' land in 1990, 2000, 2010, and 2015 reveal the following (Figure 3): In more than 20 years, from 1990 to 2015, the distributional spatial pattern of major industrial parks in the Beijing-Tianjin-Hebei urban agglomeration changed continuously while simultaneously exhibiting the characteristics of concentration and diffusion. In the early 1990s, the distribution of industrial park land in the Beijing-Tianjin-Hebei region was relatively scattered and the entire region was dominated by low-density zones. Only a few small high-density zones were formed in Beijing and Tianjin, and a small range of low- to moderate-density zones was distributed around the high-density zones. The density of the industrial parks surrounding the Tangshan urban area was higher than that of the surrounding areas, whereas the peripheral areas were mainly low- to moderate-density and low-density zones. In other cities with scattered industrial parks, the density was low. Compared with the results for 1990, the density of industrial parks increased in many cities in 2000. The most obvious change was the significant expansion of high-density zones of industrial parks with Beijing and Tianjin as the core cities. Among them, the original high-density zones in Beijing were expanding to Shunyi and Tongzhou to form two prominent moderate- to high-density zones, whereas moderate-density zones were observed in Huairou, in the north, and Fangshan, in the southwest. In Tianjin, the two high-density zones formed in 1990 expanded into one zone, and another high-density zone was formed in the Binhai New Area. Langfang City in Hebei Province, which is closely connected with Beijing and Tianjin, also has a high-density industrial park zone. In addition, the Caofeidian District of Tangshan included a highdensity zone and a high-density zone of industrial parks emerged in Leting County. By 2010, the industrial parks in Beijing had developed further and continuously expanded to Shunyi and Tongzhou. In Tianjin, high-density zones merged to form a massive highdensity zone including the core of the city center and encompassing Beichen, Dongli, Jinnan, and Xiqing districts and the Binhai New Area. In Hebei Province, in addition to Tangshan and Langfang, Qinhuangdao, Cangzhou, Shijiazhuang, Hengshui, and Handan formed several moderate-density and moderate- to high-density zones. By 2015, the high-density zones centered in Caofeidian in Tangshan had expanded to some extent; further, highdensity zones appeared in parts of Shijiazhuang and Handan, the moderate-density zones in Hengshui expanded to some extent, and a moderate- to high-density zone centered in the central urban area appeared. Except for the parks in these prefecture-level cities, those in other cities of Hebei Province remained relatively scattered, whereas the industrial park land in Beijing and Tianjin did not record significant expansion after 2010.

In general, the land spaces of industrial parks in the Beijing-Tianjin-Hebei urban agglomeration have seen an evolving trend from a pattern of single centers within specific locations to multiple centers in the entire region over the years. Beijing and Tianjin have 
always been high-density zones. The number and scale of industrial parks increased and maintained a consistent high-density level after decades of development, showing a significant tendency toward centralization. The density of industrial parks in all parts of Hebei increased. The number of outlying industrial parks increased significantly, particularly in the eastern and southern regions. However, the industrial parks in Zhangjiakou, Chengde, and Baoding, in the north, still remain scattered, with most of the areas being classified as low-density and low- to moderate-density zones.
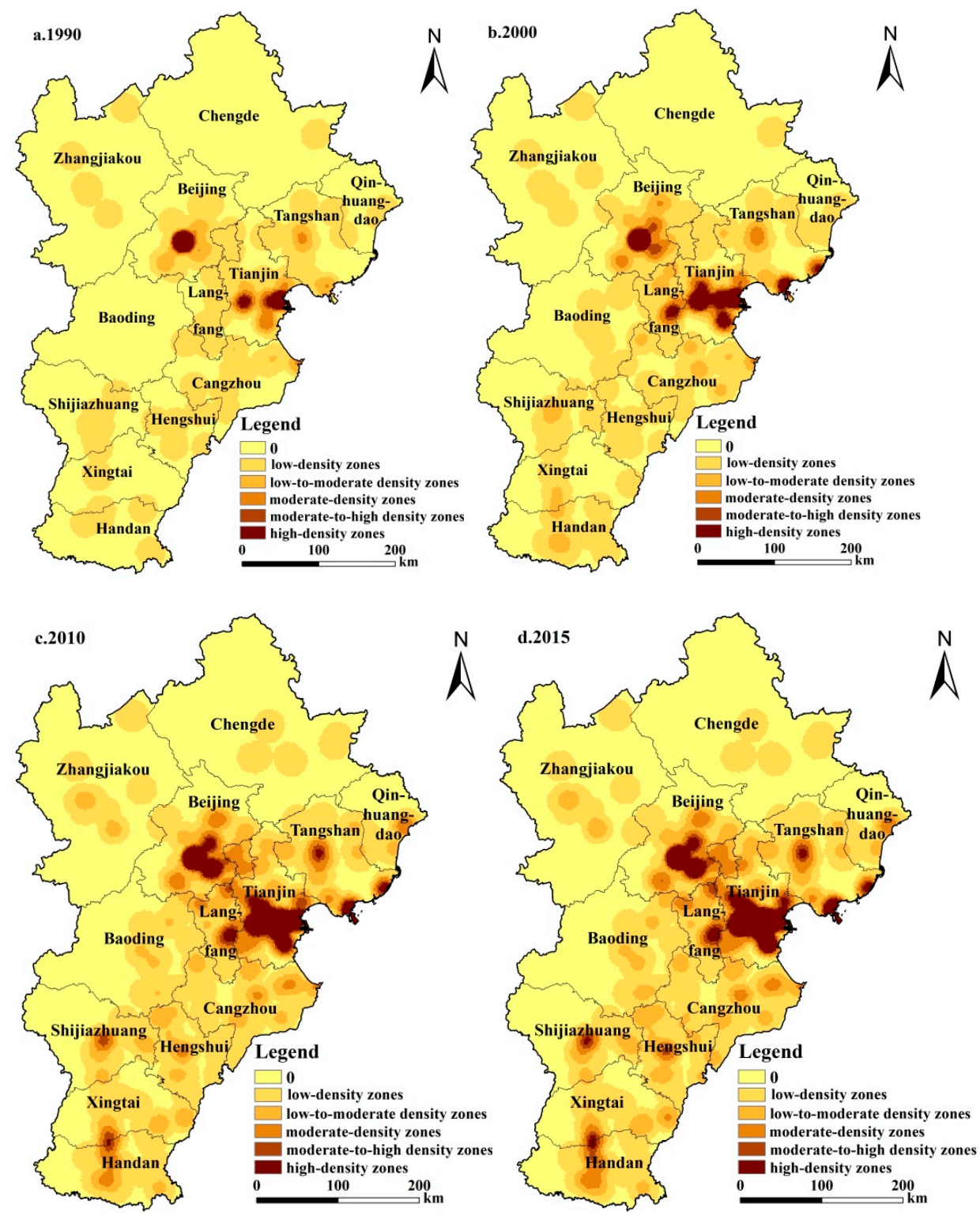

Figure 3. Kernel density analysis of industrial parks in Beijing-Tianjin-Hebei urban agglomeration from 1990 to 2015.

\subsection{Spatial Modes of the Land Use Evolution of Industrial Parks}

Based on the calculation of the landscape expansion index (LEI) values of all newly added industrial park patches in the 13 cities of the Beijing-Tianjin-Hebei urban agglomeration in the three stages of 1990-2000, 2000-2010, and 2010-2015, further statistics are derived for the total patch area and the proportion in the total area as per infilling expansion, edge-expansion, and outlying expansion according to the LEI values (Table 3). Based on the calculation results, we analyze the expansion modes of each city for different periods as follows: 
Table 3. The areas of industrial parks' as per different expansion modes in the Beijing-Tianjin-Hebei urban agglomeration (km²; \%).

\begin{tabular}{|c|c|c|c|c|c|c|c|c|c|c|}
\hline & & \multicolumn{3}{|c|}{$1990-2000$} & \multicolumn{3}{|c|}{ 2000-2010 } & \multicolumn{3}{|c|}{ 2010-2015 } \\
\hline & & $\begin{array}{c}\text { Edge- } \\
\text { Expansion }\end{array}$ & $\begin{array}{c}\text { Outlying } \\
\text { Expansion }\end{array}$ & $\begin{array}{l}\text { Infilling } \\
\text { Expansion }\end{array}$ & $\begin{array}{c}\text { Edge- } \\
\text { Expansion }\end{array}$ & $\begin{array}{l}\text { Outlying } \\
\text { Expansion }\end{array}$ & $\begin{array}{l}\text { Infilling } \\
\text { Expansion }\end{array}$ & $\begin{array}{c}\text { Edge- } \\
\text { Expansion }\end{array}$ & $\begin{array}{l}\text { Outlying } \\
\text { Expansion }\end{array}$ & $\begin{array}{c}\text { Infilling } \\
\text { Expansion }\end{array}$ \\
\hline Beijing & Area & 62.99 & 15.96 & 69.20 & 65.69 & 4.31 & 115.23 & 15.33 & 0.00 & 110.88 \\
\hline \multirow{2}{*}{ Tianjin } & Area & 118.55 & 20.57 & 0.00 & 168.46 & 43.48 & 59.72 & 135.27 & 0.00 & 203.33 \\
\hline & Proportion & 85.22 & 14.78 & 0.00 & 62.01 & 16.00 & 21.98 & 39.95 & 0.00 & 60.05 \\
\hline \multirow{2}{*}{ Shijiazhuang } & Area & 5.86 & 5.88 & 0.00 & 19.83 & 8.89 & 0.00 & 19.00 & 1.39 & 9.22 \\
\hline & Proportion & 49.89 & 50.11 & 0.00 & 69.05 & 30.95 & 0.00 & 64.15 & 4.71 & 31.14 \\
\hline Tangshan & Proportion & 25.45 & 74.55 & 0.00 & 38.29 & 52.78 & 8.94 & 94.93 & 0.34 & 4.73 \\
\hline \multirow{2}{*}{ Qinhuangdao } & Area & 1.76 & 1.86 & 0.00 & 7.03 & 9.38 & 0.00 & 2.29 & 0.00 & 0.00 \\
\hline & Proportion & 48.53 & 51.47 & 0.00 & 42.83 & 57.17 & 0.00 & 100.00 & 0.00 & 0.00 \\
\hline \multirow[b]{2}{*}{ Handan } & Area & 2.53 & 13.00 & 0.00 & 19.18 & 17.93 & 1.77 & 16.27 & 0.00 & 29.62 \\
\hline & Proportion & 16.29 & 83.71 & 0.00 & 49.32 & 46.12 & 4.56 & 35.45 & 0.00 & 64.55 \\
\hline \multirow{2}{*}{ Xingtai } & Area & 0.99 & 6.47 & 0.00 & 23.63 & 13.82 & 0.40 & 21.70 & 0.57 & 15.10 \\
\hline & Proportion & 13.27 & 86.73 & 0.00 & 62.42 & 36.52 & 1.06 & 58.07 & 1.51 & 40.41 \\
\hline \multirow{2}{*}{ Baoding } & Area & 0.00 & 3.14 & 0.00 & 6.52 & 8.15 & 0.00 & 13.93 & 0.40 & 3.46 \\
\hline & Proportion & 0.00 & 100.00 & 0.00 & 44.47 & 55.53 & 0.00 & 78.31 & 2.23 & 19.47 \\
\hline Zhangiiakou & Proportion & 63.71 & 36.29 & 0.00 & 68.51 & 31.49 & 0.00 & 44.65 & 3.33 & 52.02 \\
\hline \multirow{2}{*}{ Chengde } & Area & 0.00 & 0.00 & 0.00 & 0.24 & 3.85 & 0.00 & 2.64 & 0.08 & 0.00 \\
\hline & Proportion & 0.00 & 0.00 & 0.00 & 5.98 & 94.02 & 0.00 & 96.89 & 3.11 & 0.00 \\
\hline \multirow{2}{*}{ Cangzhou } & Area & 11.03 & 7.69 & 0.00 & 28.41 & 10.99 & 0.00 & 37.97 & 0.18 & 4.89 \\
\hline & Proportion & 58.92 & 41.08 & 0.00 & 72.11 & 27.89 & 0.00 & 88.22 & 0.42 & 11.36 \\
\hline \multirow{2}{*}{ Langfang } & Area & 20.07 & 19.81 & 0.00 & 26.32 & 18.53 & 2.24 & 20.61 & 0.96 & 26.83 \\
\hline & Proportion & 50.32 & 49.68 & 0.00 & 55.89 & 39.34 & 4.77 & 42.58 & 1.98 & 55.43 \\
\hline \multirow{2}{*}{ Hengshui } & Area & 1.95 & 0.56 & 0.00 & 12.01 & 13.91 & 0.00 & 38.19 & 2.19 & 0.92 \\
\hline & Proportion & 77.83 & 22.17 & 0.00 & 46.33 & 53.67 & 0.00 & 92.49 & 5.30 & 2.22 \\
\hline
\end{tabular}


3.3.1. Edge-Expansion in Core Areas and Minimal Expansion in Peripheral Areas: 1990-2000

From 1990 to 2000, Beijing's industrial parks mainly underwent edge-expansion and infilling expansion, corresponding to areas of 62.99 and $69.20 \mathrm{~km}^{2}$, respectively. Further, Tianjin's industrial parks underwent edge-expansion for an area up to $118.55 \mathrm{~km}^{2}$. Although edge-expansion or outlying expansion were observed in cities such as Tangshan and Langfang in the near-core circle of Beijing and Tianjin, the expansion size was relatively small. The land added to industrial parks in outer-circle cities was difficult to characterize and had a small expansion size. Generally, in the late 1990s, except for Beijing and Tianjin as core cities and Tangshan and Langfang in the near-core circle, the newly added industrial park spaces were extremely scattered and did not show any notable conglomeration pattern in cities such as Cangzhou, Shijiazhuang, and Xingtai.

3.3.2. Edge-Expansions and Infilling Expansions in Core Areas and Outlying Expansions in Peripheral Areas: 2000-2010

From 2000 to 2010, large-scale edge-expansions were observed in core and near-core cities, including Beijing, Tianjin, Tangshan, and Langfang. In Beijing, considerable edgeexpansions around original high-density zones were observed toward the north, southeast, and south, although with considerably low rates of expansion. In Tianjin, industrial parks underwent edge-expansions by $168.46 \mathrm{~km}^{2}$, which accounted for $62.01 \%$ of the total area of expansions and formed a spatial agglomeration of concentrated and contiguous industrial parks. Except for the two core cities of Beijing and Tianjin, many cities, such as Tangshan, Shijiazhuang, Qinhuangdao, Handan, Xingtai, Baoding, Zhangjiakou, Chengde, Cangzhou, Langfang, and Hengshui, witnessed outlying expansions of industrial parks. For most of the cities, the areas of outlying expansions were more than $10 \mathrm{~km}^{2}$ and the agglomeration of industrial parks gradually became apparent. Meanwhile, infilling expansions were observed in many industrial parks. Beijing recorded the largest area $\left(115.23 \mathrm{~km}^{2}\right)$ under this expansion mode, followed by Tianjin $\left(59.72 \mathrm{~km}^{2}\right)$. This expansion mode was also observed in Tangshan, Langfang, Handan, near-core circle cities, and the core cities of Beijing and Tianjin.

3.3.3. Prevalence of Infilling Expansions in Core Areas and Edge-Expansions in Peripheral Areas: 2010-2015

From 2010 to 2015, all expansions of established industrial park agglomerations were primarily driven by internal reconstruction and transformation in the infilling expansion mode. The major industrial parks in the Beijing-Tianjin-Hebei urban agglomeration underwent significant development, leading to scale effects. In the two core cities of Beijing and Tianjin, industrial parks mostly underwent infilling expansions. In small and medium-sized cities, such as Shijiazhuang, Tangshan, Handan, Xingtai, Baoding, Cangzhou, and Langfang, the characteristics of edge-expansions were notable, the areas becoming concentrated for industrial park land expansion. In some of the cities, such as Langfang, Handan, and Xingtai, infilling expansions were also observed. At this stage, the industrial parks in core cities mainly underwent infilling expansion and the established industrial park agglomeration in small and medium-sized cities continued to expand by spreading. That is to say, in outer-circle cities, significant expansions continued to occur.

\section{Discussion}

\subsection{Factors Influencing the Expansion of Industrial Parks in Beijing-Tianjin-Hebei}

The driving factors and dynamic mechanism of urban land expansion have always been the focus of academic attention. Many studies have conducted analysis from demographic, social, economic, and policy perspectives $[47,48]$. This paper discusses the main factors affecting the land expansion of industrial parks in Beijing-Tianjin-Hebei, which are as follows. 
(1) Natural background conditions: Industrial activities are bound to be concentrated in areas with the most suitable natural conditions. Therefore, location-specific production often occurs at a sizable scale. It is argued that natural conditions form the foundation of regional development. Taking the terrain and landform as examples, the Beijing-Tianjin-Hebei urban agglomeration has a mountainous terrain in the northwestern region and a flat terrain in the southeast. The main industrial parks are located in the flat, plain areas. Such areas generally include convenient conditions for production activity, planning and implementation, infrastructure construction, and daily activities and transportation. By contrast, Zhangiiakou and Chengde, in the northwest, are mostly located on plateaus, mountains, or loess hilly-gully regions. The characteristics of their terrain make them important catchment areas and a natural ecological barrier of the Beijing-Tianjin-Hebei agglomeration. The regions' relatively strict policies on industrial development, resource exploitation, and environmental protection constrain the planning and building of industrial parks, particularly parks for secondary industries. Therefore, in the Beijing-Tianjin-Hebei urban agglomeration, major industrial parks are concentrated in the eastern and southern regions; in northern areas, such as Zhangjiakou and Chengde, industrial parks generally have low-density or low- to moderate-density distributions.

(2) Transportation access: Transportation access is an important driving factor of regional industrial distribution and spatial changes [49]. Studies show that improving a region's transportation access can affect the establishment of businesses and formation of industrial layouts by reducing business costs and promoting the clustering of business activities [50]. The Beijing-Tianjin-Hebei region functions as a transportation hub in China. Major cities, such as Beijing, Tianjin, and Shijiazhuang, are located at the intersection of several national highways and railways. The Beijing-Tianjin-Hebei urban agglomeration imports international crude oil, iron ore, and other mineral resources through Tangshan Port, Tianjin Port, Cangzhou Port, and other coastal ports and, thereby, ensures the development of regional iron, steel, and petrochemical industries. In addition, an efficient land and sea transportation infrastructure facilitates the functioning of rapid transportation services, which, in turn, promotes the adjustment of industrial structures and relocation of productive assets [51]. Therefore, traffic location factors should be a determinant of the expansion trend and pattern of industrial parks. Future studies should examine these factors in depth.

(3) Regional and industrial policy guidance: In China, the government zones industrial parks to cluster business activities in a region-wise development strategy. The guiding and regulating of governmental policies and planning are fundamental to the temporal and spatial evolution of industrial parks' land use [52]. For instance, in accordance with governmental planning, service sector businesses occupy most of the spaces in Beijing's central urban area, whereas secondary sector industries dominate the peripheral areas. Since secondary sector development tends to be land intensive, the emergence of an expansion trend is observed in Beijing's peripheral areas. Tianjin is a traditional industrial city in northern China. Following the incorporation of the Binhai New Area development into national strategies, massive businesses and creative ideas have been flocking to Tianjin. Moreover, numerous significant pilot reform initiatives introduced in the city promote the continuous development of industrial parks centered in the Binhai New Area and expand them in peripheral areas. Meanwhile, the incorporation of regional planning for the Beijing-Tianjin-Hebei metropolitan area into national strategic planning plays a significant role in market incubation, reversing excessive clustering, and promoting development in peripheral areas. The overall strategy that emphasizes regional coordinated development and the trend of relocating industrial assets from Beijing and Tianjin to enhance cooperation and extend the industrial chain facilitate the relocation of productive industrial assets, particularly those for heavy industries, preferably to cities in Hebei. Moreover, Hebei has proposed a development strategy to build a strong coastal province. To develop 
their economies through industrial investments, in addition to traditional industrial cities, such as Tangshan, many cities, including Qinhuangdao, Cangzhou, Langfang, Xingtai, and Handan, are attracting various relocated assets by leveraging existing capabilities in raw material processing, equipment manufacturing, and consumer goods production and offering favorable migrant and land policies. Further, influenced by the regional and industrial policies and planning in the Beijing-Tianjin-Hebei region, major industrial parks are expanding to the east coast and the south.

(4) Some other influencing factors: The expansion of industrial parks is not only a geographical phenomenon but also an economic phenomenon. Therefore, many economic factors also affect the location of a park and its expansion. Among them, labor and land, as the most important resource endowment components of a region, often affect the region's industrial development positioning and future changes. For the Beijing-Tianjin-Hebei urban agglomeration, the Hebei area outside the BeijingTianjin dual core has become the key area carrying all kinds of industrial transfer parks with lower manpower and labor costs, as well as more abundant available land resources, becoming the main area for industrial parks' expansion. Thus, it has led to significant edge-expansion of the parks in the periphery of the Beijing-Tianjin dual core. From the perspective of policy factors, in addition to the main regional and industrial policies mentioned above, fiscal and tax policies and environmental policies are important factors affecting the development and change of regional industries and thus affecting the location and expansion of industrial parks. In the context of the near saturation of industrial land in Beijing and Tianjin, as well as serious regional environmental pollution and prominent urban diseases in Beijing and Tianjin, fiscal funds and environmental protection policies have been used to improve the carrying capacity of industrial transfer in Hebei. In particular, tax incentives are being used to encourage regional industries to transfer to the Beijing-Tianjin area, so as to promote the further expansion of industrial parks in these areas.

\subsection{Mechanisms of the Spatial Expansion Modes of Beijing-Tianjin-Hebei Industrial Parks}

In different historical periods, social-economic development backgrounds and regional industrial development needs have been different. Therefore, discussing the expansion characteristics of regional industrial parks and their influence mechanisms over different time periods is helpful in understanding the dynamic characteristics and grasping the evolution trend of industrial parks expansion in the Beijing-Tianjin-Hebei region.

(1) 1990-2000: According to the history of industrialization and industrial park development in the Beijing-Tianjin-Hebei agglomeration, Beijing and Tianjin already had a well-developed industrial sector as early as the 1990s. The development zones in Beijing are mostly built on electromechanical and high-tech industries. For example, Beijing's Zhongguancun Science Park has experienced the following development patterns: "one park, three subzones," "one park, five subzones," and "one park, subzones." In addition, the construction of the Beijing Economic-Technological Development Area (also known as the Yizhuang Development Area) was started in 1992 and the area was subsequently approved by the State Council as the only state-level economic and technological development zone in Beijing. Meanwhile, many city-level economic development zones and parks promoting the secondary sector were built and established in Shunyi, Changping, Pinggu, and Miyun districts and counties around Beijing. Industrial parks also expanded into the northeastern region of Beijing. During the same period, Tianjin established several industrial parks and development zones sustained by its industrial bases, economic foundation, and coastal opening-up conditions. Among them, the Tianjin Economic-Technological Development Area was one of the first state-level development zones. The Tangshan City of Hebei Province is closely connected to the core circle of Beijing and Tianjin. Due to the city's early start in terms of industrial development compared to other cities, its industrial parks were initially concentrated at the edge of the urban area, such as the east of the Lubei 
District, the Guye District, the Kaiping District, and the Fengrun District. Since the 1990s, the industrial agglomeration area of Tangshan has been undergoing expansion. With the emergence of the Caofeidian Industrial Zone and the Laoting Port Industrial Agglomeration Area, industrial parks developed in southeastern coastal areas. In addition, the industrial parks in Langfang City led the city's development by maintaining their superior location conditions around the core of the Beijing-Tianjin and Bohai Rim economic circle. Further, the Yanjiao Economic and Technological Development Area, which was established in 1992, was upgraded to a provincial high-technology zone in 1999 and its spatial scale and industrial level underwent significant improvement.

(2) 2000-2010: In this period, despite the expansion of industrial park land in BeijingTianjin-Hebei, the range and spatial pattern of high-density industrial parks remained largely unchanged. During this period, the expansion of industrial park land use in economically developed cities in the core and near-core circles was stabilized. For cities in the outer circle, particularly those to the south of Beijing and Tianjin, the expansion of industrial parks became prominent with a sharp increase in the number of new industrial parks. This increase was partly driven by strengthened economic development at the county level, as well as the radiation and push-and-pull effects of core cities. In some counties and cities, urban renovation programs also promoted the establishment of new industrial parks. Accordingly, to date, all the districts and counties in Hebei have established industrial parks. Local development and active accommodation of relocated assets expand the coverage of industrial parks in a county-specific mode. The new industrial parks in the broader periphery areas present an outlying expansion pattern. Generally, the industrial parks in the Beijing-Tianjin-Hebei urban agglomeration have formed a spatial pattern of multiple centers with the diversified spatial distribution of industrial park land.

(3) 2010-2015: In this period, the expansion of industrial parks in the core cities of Beijing and Tianjin slowed down significantly, particularly in Beijing. Since only limited land was available for industrial use, industrial spaces were concentrated in the east and south of peripheral areas. Industrial park expansions were largely observed in small and medium-sized cities, such as Cangzhou, Shijiazhuang, Hengshui, Xingtai, and Handan. In core cities, where the constraints on available land resources and planning became increasingly tight, significant reductions in the freedom of land use and the lack of adequate backup spaces prevented the continuous progress of industrialization. Furthermore, under the national strategy of promoting coordinated development of the Beijing-Tianjin-Hebei agglomeration, the relocation of the nonessential functions of Beijing as the capital city was associated with the adjustment of the regional industrial structure and transfer of industrial functions. Small and medium-sized cities around the core cities allocated more space to accommodate further expansion of industrial activities and chose the edge-expansion mode [53]. These developments explain the notable expansion of industrial park land use in the outer circle of core cities.

\subsection{Development Directions of Industrial Parks with Different Expansion Modes}

The results of our study show that in the Beijing-Tianjin-Hebei urban agglomeration with an obvious dual-core structure, the development and evolution of industrial park land is affected by the radiation of the core city and the spatial evolution modes of the industrial parks present unbalanced characteristics. The Beijing-Tianjin-Hebei urban agglomeration is a region with typical dual economic structure, and the imbalance of its industrial development is prominent. The two core cities of Beijing and Tianjin gather the country's best resources, such as talents, policies, finance, technology, innovation, education, culture, medical care, and technology. The high-end population and industries are highly concentrated here, and the industrial development of the two cities presents a pattern dominated by modern service industry, high-end manufacturing industry, and 
high-tech industry. In Hebei, due to the weak regional economic foundation, the lock-in of the industrial development path, and the deviation of development priorities, the industry mainly focuses on the manufacture of resource products. An important feature of the development differences of industries in terms of space is that the regional imbalance of industrial spatial distribution is significant. The main industrial bases and parks are basically concentrated in the core areas of Beijing, Tianjin, and Tangshan. Therefore, for cities with different locations and different economic and industrial development stages, the construction directions and paths of industrial parks are also different.

In core cities, such as Beijing and Tianjin, the focus of urban development will shift from scale growth to quality improvement; the functional positioning and development focus of industrial parks will also change accordingly. Focusing on the structural optimization of park functions and improvement of park governance becomes necessary. Edge-expansion should be replaced by the free combination of functions to improve the efficiency of space and land use. The parks serving specific industries should be transformed and upgraded to comprehensively facilitate better coordination. Enhancing the benefits of clustering activities by upgrading industries and providing better support services helps realize intensive development in the form of infilling expansions. Specifically, it is necessary to implement the industrial park renewal strategy, focus on evaluating existing industries, clarify the low-end industry exit list and mechanism, and accelerate the transformation and upgrading of retained industries. To meet the needs of improving the level of in-gathering development of industrial parks, the optimized construction of a set of facilities should be promoted from two aspects: supporting production services and supporting living services. Policy support and innovation should be implemented from the aspects of spatial layout optimization and spatial quality improvement. Meanwhile, considering the push effect of core cities' urbanization on industrial park development, many industrial parks cannot be simply considered the media to expand urban industrial functional spaces. By combining productive functions and public services, cities can support industrial development and population growth, thereby enhancing intensive land use integrating working space, residential, recreational, and transportation functions. In other words, this helps build advanced industrial parks that merge industrial and urban functions.

The key cities around the core area, such as Tangshan and Langfang, build on their solid industrial base to optimize their industrial structure. Their industrial parks are currently expanding in the infilling and edge-expansion modes and, in some cases, the latter plays only a supportive role. Industrial parks with such expansion mode should focus on intensive development by creating a good business environment, ecological environment, and production environment to attract high-quality tenants and talents. Governments should improve park functions and identify the opportunities for intensive land use so that the land per unit area can carry more industries, absorb more people, and increase the intensity of land investment and output. For example, in the assessment of development zones, the output per unit land area and the GDP per capita per square kilometer of land should be calculated, guiding sustainable park development.

For other small and medium-sized cities, since their industrial parks endeavor to attract more tenants to boost industrial development or even incubate industrial clusters, relatively extensive land use is required. Most businesses engage in labor-intensive processing and manufacturing operations, and governments have to offer low land costs to attract foreign investments, technologies, and businesses. Therefore, the edge-expansion mode remains prominent in industrial park development. Further, governments should enhance land management and coordination among industries to improve the parks' floor area ratio to enable highly efficient and intensive use of resources. Moreover, they should plan adequate spaces for public services and municipal infrastructure to ensure optimal spatial layouts and building characteristics of industrial parks to satisfy the requirements of modern industrial development. Specifically, a comprehensive plan should be implemented and policy capital investment should be increased to ensure important construction projects in the park. The parks should constantly explore diversified investment and financing 
methods and introduce high-quality enterprises and projects. It is also necessary to intensify efforts to undertake industrial transfer, promote the upgrading of local enterprises, and enhance the endogenous driving force for the parks' development. In addition, land resources should be reasonably allocated and the site selection, scale plan, and operation management of standard factory buildings in the park should be carefully planned to ensure the promotion of standardized factory building and provide convenient conditions for enterprises to settle in.

\section{Conclusions}

In this study, remote sensing and GIS techniques were used to collect the spatial data of major industrial parks that assume the economic production role in the Beijing-TianjinHebei urban agglomeration. The data for 1990, 2000, 2010, and 2015 were obtained by interpreting high-resolution satellite images. Further, the study identified the patterns and characteristics of industrial park land use expansion from the spatial perspective. Subsequently, it examined the major factors that influence the parks' spatial evolution and its formation mechanisms. After considering the latest developments status and dynamic trends of industrial park expansion, some countermeasures and paths to optimize the parks' spatial development are proposed. As the research has demonstrated: (1) During the studied periods, the land area of major industrial parks in Beijing-Tianjin-Hebei increased continuously, but with diminishing average annual growth rates of $11.51 \%, 8.17 \%$, and $3.38 \%$ for 1990-2000, 2000-2010, and 2010-2015, respectively. The space of industrial parks has been evolving toward a more intensive and efficient direction. (2) In terms of spatial layout, the land space of the industrial parks in the Beijing-Tianjin-Hebei urban agglomeration presented an evolutionary trend from local single center to global multicenter. The density of industrial parks has always been high in Beijing and Tianjin, with the number and scale continuously expanding and maintaining high-density level, and the development trend tends to be concentrated and contiguous. Further, it increased throughout Hebei during the studied periods. The industrial parks present a significant outlying-type expansion pattern. More industrial parks are concentrated in the southeast and less in the north. (3) Regarding the expansion modes determined according to the calculated LEIs, the period 1990-2000 mainly witnessed edge-expansions in core areas, such as Beijing and Tianjin, and limited expansions without a notable concentration in peripheral cities that had not yet formed an obvious spatial cluster pattern; in 2000-2010, mainly edge-expansions and infilling expansions occurred in core cities and characteristically outlying expansions occurred, forming a more significant cluster of industrial parks than the previous period in peripheral ones; finally, in 2010-2015, infilling expansions largely occurred in core cities and edge-expansions occurred in small and medium-sized cities.

Unlike earlier studies, this study described the temporal and spatial evolutionary pattern of industrial park groups in a specific region. It focused on the pattern changes of such functional spatial media and proposed countermeasures to optimize regional development spaces. The current study's advantage over case studies on individual industrial parks is that the current study presented a medium- to macroscale picture of spatial evolution to clarify its driving mechanisms and the parks' future development trends. However, one limitation of this study is that it focused on the spatial expansion patterns of industrial parks in the Beijing-Tianjin-Hebei urban agglomeration and only briefly discussed the factors affecting the spatial expansions. As an important carrier of economic activities, industrial parks undergo a spatial evolution that is affected by economic development, industrial change, and policy evolution, and the driving mechanism of each factor affecting spatial evolution is complex. Hence, future studies should more meticulously examine the driving mechanisms and propose more robust and precise countermeasures and suggestions to optimize regional industrial park development. 
Author Contributions: Conceptualization, L.M. and L.K.; methodology, L.K.; software, L.K.; validation, L.M.; formal analysis, L.K.; investigation, L.K.; resources, L.M. and L.K.; data curation, L.M. and L.K.; writing — original draft preparation, L.K.; writing—review and editing, L.M.; visualization, L.K.; supervision, L.M.; project administration, L.M.; funding acquisition, L.M. and L.K. All authors have read and agreed to the published version of the manuscript.

Funding: This research was funded by the Strategic Priority Research Program (A) of the Chinese Academy of Sciences (No. XDA19040403) and the National Natural Science Foundation of China (Grant No. 41801114).

Acknowledgments: We thank Yi Liu and Yu Yang for providing valuable comments on an earlier version of the manuscript.

Conflicts of Interest: The authors declare no conflict of interest.

\section{References}

1. Das, D.; Lam, T. High-tech utopianism: Chinese and Indian science parks in the neo-liberal turn. BJHS Themes 2016, 1, 221-238. [CrossRef]

2. Huang, W.-J.; Fernández-Maldonado, A.M. High-tech development and spatial planning: Comparing the Netherlands and Taiwan from an institutional perspective. Eur. Plan. Stud. 2016, 24, 1662-1683. [CrossRef]

3. Zhuang, L.; Ye, C. Changing imbalance: Spatial production of national high-tech industrial development zones in China (1988-2018). Land Use Policy 2020, 94, 104512. [CrossRef]

4. Cartier, C. 'Zone Fever', the Arable Land Debate, and Real EstateSpeculation: China's evolving land use regime and its geographicalcontradictions. J. Contemp. China 2001, 10, 445-469. [CrossRef]

5. Zhang, J. Interjurisdictional competition for FDI: The case of China'sdevelopment zone fever? Reg. Sci. Urban Econ. 2011, 41, 145-159. [CrossRef]

6. Sun, Y.; Ma, A.; Su, H.; Su, S.; Chen, F.; Wang, W.; Weng, M. Does the establishment of development zones really improve industrial land use efficiency? Implications for China's high-quality development policy. Land Use Policy 2019, $90,104265$. [CrossRef]

7. Zeng, D.Z. Global Experiences with Special Economic Zones: Focus on China and Africa. World Bank Policy Res. Work. Pap. 2015, $7240,1-17$

8. Howard, E. Garden Cities of Tomorrow; The MIT Press: Cambridge, MA, USA, 1976.

9. Phillips, D.R. New Town in East and South-East Asia; Oxford University Press: Oxford, UK, 1987.

10. Bristow, R. Hong Kong's New Towns: A Selective Review; Oxford University Press: Oxford, UK, 1989.

11. Thomas, R. Book Review: New Town, Home Town: Colin Ward, 1993 London: Calouste Gulbenkian Foundation 159 pp. Urban Stud. 1994. [CrossRef]

12. Bloom, N.R. Suburban Alchemy: 1960's New Towns and the Transformation of the American Dream; Ohio State University Press: Colunbus, OH, USA, 2001.

13. Justin, T. Growth of industry clusters and innovation:lessons from Beijing Zhongguancun. Sci. Park. J. Bus. Ventur. 2006, 21, 827-850.

14. Sargent, J.; Matthews, L. What Happens When Relative Costs Increase in Export Processing Zones? Technology, Regional Production Networks, and Mexico's Maquiladoras. World Dev. 2004, 32, 2015-2030. [CrossRef]

15. Cling, J.P.; Razafindrakoto, M.; Roubaud, F. Export processing zones in madagascar: A success story under threat? World Dev. 2005, 33, 785-803. [CrossRef]

16. Jenkins, M. Sourcing patterns of firms in Export Processing Zones (EPZs): An empirical analysis of firm-level determinants. J. Bus. Res. 2006, 59, 331-334. [CrossRef]

17. Li, G.W. Spatial distribution, growth process and dominant industries of province-level development zones in China. Urban Stud. 2009, 16, 1-6. (In Chinese)

18. Feng, X.Z.; Wang, S.J.; Zhang, Y. Development zones' function reforming and structure optimization in the central city poparization's background. Urban Stud. 2010, 17, 5-8. (In Chinese)

19. Zhu, X.; Li, Y.; Zhang, P.; Wei, Y.; Zheng, X.; Xie, L. Temporal-spatial characterisics of urban land use efficiency of China's 35 mega cities based on DEA: Decomposing technology and scale efficiency. Land Use Policy 2019, 88, 104083. [CrossRef]

20. Zhang, Y. The spatial expansion of development zones and urban spatial restructuring-the cases of Suzhou, Wuxi and Changzhou. Urban Plan. Forum 2007, 1, 49-54. (In Chinese)

21. Chen, R.J. Study on Space Growth Mechanism and Optimization Strategy of the Urban Development Zone. Ph.D. Thesis, Huazhong University of Science and Technology, Wuhan, China, 2009. (In Chinese)

22. He, C.; Wei, Y.D.; Pan, F. Geographical Concentration of Manufacturing Industries in China: The Importance of Spatial and Industrial Scales. Eurasian Geogr. Econ. 2007, 48, 603-625. [CrossRef]

23. Wei, N.; Chen, H.; Xu, L. A comparative study on evaluation methods of land intensive utilization in development zone. Resour. Environ. Yangtze Basin 2017, 26, 1556-1563. (In Chinese) 
24. Zhang, H.; Sonobe, T. Development of Science and Technology Parks in China, 1988-2008. Economics 2011, 5, 1-25. [CrossRef]

25. Wang, X.P.; Cui, G.H. The study on the space scale and economic returns of the Chinese urban development zone. City Plan. Rev. 2003, 27, 6-12. (In Chinese)

26. Liu, Y. Introduction to land use and rural sustainability in China. Land Use Policy 2018, 74, 1-4. [CrossRef]

27. Pan, M.M.; Song, H.Y. Transformation and Upgrading of Old Industrial Zones on Collective Land: Empirical Study on Revitalization in Nanshan. Habitat Int. 2017, 65, 1-12. [CrossRef]

28. Cheng, J. Analyzing the factors influencing the choice of the government on leasing different types of land uses: Evidence from Shanghai of China. Land Use Policy 2019, 90, 104303. [CrossRef]

29. Alder, S.; Shao, L.; Zilibotti, F. Economic reforms and industrial policy in a panel of Chinese cities. J. Econ. Growth 2016, 21, 305-349. [CrossRef]

30. Xiong, C.; Lu, J.Y.; Niu, F.Q. Urban Industrial Land Expansion and Its Influencing Factors in Shunde: 1995-2017. J. Complex. 2020, 2020, 1-12. [CrossRef]

31. Lu, X.H. Land administration and land use in development zones. China Land Sci. 2004, 18, 40-44. (In Chinese)

32. Cheng, H.; Liu, Y.; He, S.; Shaw, D. From development zones to edge urban areas in China: A case study of Nansha, Guangzhou City. Cities 2017, 71, 110-122. [CrossRef]

33. Hu, W.Q.; Tian, J.P.; Chen, L.J. An industrial structure adjustment model to facilitate high-quality development of an eco-industrial park. Sci. Total Environ. 2021, 766, 142502. [CrossRef] [PubMed]

34. Yuan, X.G.; Wang, X.P. Study on the reference of marginal cities to the redevelopment of development zones in China -taking Ningbo Economic and Technological Development Zone as an example. Urban Plan. Forum 2010, 6, 95-101. (In Chinese)

35. Zeng, G.; Liefner, I.; Si, Y. The role of high-tech parks in China's regional economy: Empirical evidence from the IC industry in the Zhangjiang High-tech Park, Shanghai. Erdkunde 2011, 65, 43-53. [CrossRef]

36. Cheng, H.; Liu, Y.; He, S.J. From development zones to "edge city" with Chinese characteristics. Urban Plan. Forum 2012, 6, 50-57. (In Chinese)

37. Geng, H.Q. A research on competitiveness evaluating criterion system for modern agricultural science-technology area. Areal Res. Dev. 2013, 32, 1-4. (In Chinese)

38. Rao, C.K.; Chen, W. Research on the spatial development of urban development area under the background of its transformation to new town: A case study of Hangzhou economic \& technological development area. City Plan. Rev. 2015, 4, 43-52. (In Chinese)

39. Wong, S.; Tang, B. Challenges to the sustainability of 'development zones': A case study of Guangzhou Development District, China. Cities 2005, 22, 303-316. [CrossRef]

40. Zhang, Z.; Shi, A. Development Zones and Evolvement of Urban Spatial Structure: A Case Study on LanZhou City. Procedia Environ. Sci. 2011, 11, 1529-1534. [CrossRef]

41. Liu, Z.G.; Zhang, J.Y.; Golubchikov, O. Edge-Urbanization: Land Policy, Development Zones, and Urban Expansion in Tianjin. Sustainability 2019, 11, 2538. [CrossRef]

42. Fang, C. Important progress and future direction of studies on China's urban agglomerations. J. Geogr. Sci. 2015, 25, 1003-1024. [CrossRef]

43. Fang, C.; Yu, D. Urban agglomeration: An evolving concept of an emerging phenomenon. Landsc. Urban Plan. 2017, 162, 126-136. [CrossRef]

44. Harrison, J.; Gu, H. Planning megaregional futures: Spatial imaginaries and megaregion formation in China. Reg. Stud. 2019, 55, 77-89. [CrossRef]

45. Fang, C.; Mao, Q.; Ni, P. Debates and explorations of scientifically selecting and hierarchically developing China's urban agglomerations. Acta Geogr. Sin. 2015, 70, 515-527. (In Chinese)

46. Liu, X.; Li, X.; Chen, Y.; Tan, Z.; Li, S.; Ai, B. A new landscape index for quantifying urban expansion using multi-temporal remotely sensed data. Landsc. Ecol. 2010, 25, 671-682. [CrossRef]

47. Hegazy, I.R.; Kaloop, M.R. Monitoring urban growth and land use change detection with GIS and remote sensing techniques in Daqahlia governorate Egypt. Int. J. Sustain. Built Environ. 2015, 4, 117-124. [CrossRef]

48. Kheir, N.; Portnov, B.A. Economic, demographic and environmental factors affecting urban land prices in the Arab sector in Israel. Land Use Policy 2016, 50, 18-527. [CrossRef]

49. Li, S. Restructuring and Optimization of Comprehensive Transportation System to Spatial Industrial Pattern. Ph.D. Thesis, Yunnan University, Kunming, China, 2016. (In Chinese)

50. Hu, A.; Liu, S. Transportation, economic growth and spillover effects: The conclusion based on the spatial econometric model. Front. Econ. China 2010, 5, 169-186. [CrossRef]

51. Weisbrod, G. Models to predict the economic development impact of transportation projects: Historical experience and new applications. Ann. Reg. Sci. 2008, 42, 519-543. [CrossRef]

52. Zhang, Z.; Li, Y. Research on the relationship of land expansion and economy growth of development zones: Taking the National Economic and Technological Development Zones as A Case. China Land Sci. 2007, 21, 4-9. (In Chinese)

53. Deng, Z.; Zhang, K. Research on manufacturing easing and undertaking location of Beijing Non-Capital Function. Econ. Geogr. 2016, 36, 94-102. (In Chinese) 